\title{
The Fine Structure of Secretory Gronules in Submandibular Glands of the Rat during Early Postnatal Development ${ }^{\prime}$
}

\author{
S. K. KIM, S. S. HAN AND C. E. NASJLETI \\ Veterans Administration Hospital, Ann Arbor, and Departments of \\ Oral Biology and Anatomy, The University of Michigan, \\ Ann Arbor 48104
}

\begin{abstract}
The secretory end-pieces of the submandibular gland of rats during the first week of postnatal development are studied with regard to the fine structure of the secretion granules in these end-pieces. The terminal ends of the secretory ducts during this period consist of two types of cells; one cell is an acinar-type and the other is a duct-type found in the gland of adult rats. The secretion granules of the acinar-type cells are similar in appearance to those of the acinar cells in the gland of adult rats, and the structure of these granules remains the same throughout the week. However, granules widely different in appearance are present in the duct-type cells, and their structure varies in different cells as well as within a single cell at different stages of development. These granules contain unusual substructures which are not found in the secretion granules of adult rats, suggesting that the granules are transitory. Granules containing short tubular profiles are predominant in the gland of one day-old rats. A large number of granules in three day-old rats contain elongated tubules. More granules of widely different substructures are present in the gland of seven day-old rats than in the gland of younger rats. The matrix of the granules in seven day-old rats is of higher density than that of the granules in younger rats. In the dense matrix of these granules, less dense tubules form fingerprint-like or somewhat more irregular patterns.
\end{abstract}

Two types of secretory granules occur in the submandibular gland of the adult rat; one type is found in acinar cells and the other type in the granulated portion of secretory ducts. The granules of the acinar cells are of a mucous type and those of the ducts are of a serous type (Shackleford and Klapper, '62). In the electron microscope, the granules of acinar cells are characterized by the ill-preserved appearance of their membrane and electron translucent interior (Scott and Pease, '59; Kurtz, '64; Tamarin and Sreebny, '65; Tamarin, '67). The granules of ducts, on the other hand, are bound by a distinct membrane and appear dense with no obvious internal structure. These granules occur in the convoluted portions of secretory ducts and are of varying density (Scott and Pease, '59; Leeson and Jacoby, '59; Tamarin and Sreebny, '65).
During the early postnatal period, submandibular glands of the rat are immature (Jacoby and Leeson, '59; Leeson and Jacoby, '59); microscopic observations of the submandibular glands of newborn rats have shown that neither typical acini nor granular ducts are present. In neonatal rats, secretory granules are located in the terminal end-piece of intralobular ducts, which has been described as the "terminal tubule" (Jacoby and Leeson, '59). The differentiation of acini and granulated ducts proceeds to completion during the first six weeks of the postnatal period.

The chemical composition of the secretory granules in the terminal tubules appears to be different from that of the granules in the mature gland, as indicated by

Received April 10, '70. Accepted June 4, '70.

1 Supported in part by United States Public Health Service, DE-02731. 
the difference in various standing reactions (Jacoby and Leeson, '59). Furthermore, the content of various enzymes in the granules of terminal tubules and in the granules of granular ducts (Fukuda, '67) is different. Such differences in chemical composition may be expected to be reflected in the structure of the secretory granules. With the exception of Leeson and Jacoby ('59), few have studied the differentiating submandibular glands of young rats with the electron microscope.

The present study describes the fine structure of serous-type, "transitory" granules in the terminal tubules of the submandibular gland of the rat during the first week of postnatal development. These granules are of an unusual structure, which is not found in the gland of adult rats. The wide variations in the fine structure of the granules are described and the possible relationship between these granules is discussed.

\section{MATERIALS AND METHODS}

Small pieces of submandibular glands were dissected from one, three and seven day-old Sprague-Dawley rats and fixed in $2 \%$ paraformaldehyde buffered to $\mathrm{pH} 7.4$ with $0.1 \mathrm{M}$ cacodylate, followed by a postfixation with $1 \% \mathrm{OsO}_{4}$ in the same buffer. The tissues were dehydrated in graded concentrations of ethanol and embedded in a mixture of epoxy resin in a routine manner (Luft, '61). Ultrathin sections were made on a Porter-Blum MT II microtome with a diamond knife, and stained with $1 \%$ aquaeous uranyl acetate (Watson, '58) and then with lead citrate (Reynolds, '63). Final preparations were studied in a Hitachi $11 \mathrm{c}$ electron microscope.

\section{OBSERVATIONS}

Observations of the submandibular gland are limited here to the terminal tubule of intralobular ducts where transitory secretory granules occur. Two types of cells constitute the terminal tubule (fig. 1). One type contains granules of ill-preserved appearance, having a content of low electron density, and resembles a mucous secreting cell. The other type contains spherical granules of an increased density, which is more clearly delineated than the former type of granules. For convenience in description these granules of the terminal tubule may be named on the basis of their appearance. The granules of lower density and ill-preserved appearance may be called the "acinar-type," as they resemble in appearance the mucous granules of acinar cells of the adult gland. The granules of higher density and of distinct contour are similar to the granules of the granulated duct in adult glands and hence may be referred to as the "duct-type."

Both types of granules are localized in the apical portion of the cytoplasm in respective cells. In cells which contain acinar-type granules, the cytoplasm is more abundant and parallel profiles of the endoplasmic reticulum are present throughout the cytoplasm. In the cells containing the duct-type granules, segments of endoplasmic reticulum are scattered mostly at the basal portion of the cytoplasm.

The structure of acinar-type granules remains the same throughout the first week of the gland development. Although the acinar-type granules are membrane bound, the membrane is not distinct in many granules. The ill-preserved interior of these granules is difficult to describe and has dense fibrillar masses of various thicknesses. Irrespective of their size, however, the acinar-type granules are of similar structure.

The duct-type granules, on the other hand, show widely different structures during the first week of postnatal development. Granules of different internal structure occur in cells of the terminal tubule at different days and sometimes within the same cell (figs. 2, 6). In cells with these granules, Golgi complexes are often found among the granules (fig. 2). However, the Golgi complexes are not as elaborate as those which are associated with the acinar-type granules. The granules of small size near the Golgi apparatus are homogeneously dense. Small bits of endoplasmic reticulum are present among the granules, as well as numerous membranefree ribosomes.

Since the duct-type granules of a single gland may vary widely in their structure, it is difficult to generalize that the granules of one structure represent a given stage of the gland development. However, there 
are certain structural variations which occur more frequently in the gland at one stage than in other stages during the week.

The granules which are most frequently encountered in the gland of one day-old rats are shown in figure 3 ; they are membrane bound and show an intermediate density. Within each granule, circular or slightly elongated structures of about 600 $\AA$ in diameter occur, which may be interpreted as short tubules. The interior diameter of these tubules is about 200 to $300 \AA$.

Granules containing more elongated tubules are also found in the gland of one day-old rats. However, the tubule-containing granules appear to be more abundant in the gland of three day-old rats (figs. $4,5)$. In these granules, the diameters of tubules are the same as the diameters of shorter tubules. The number of tubules per granule is variable among different cells within the same gland. The tubule in some granules appears to be more clumped (fig. 4) than in other granules (fig. 5).

Granules containing denser matrix occur in the terminal tubules of three day-old and seven day-old rats. These granules can be seen in figure 2 . In the dense matrix of these granules, rods or possibly tubules of lower density are present, and their diameter is also about $200 \AA$. The outline of these rods is not clear, and patches of material which are even denser than the matrix occur at the periphery of the granules.

More granules of widely varying structures occur in the terminal tubules of seven day-old rats than in younger rats, as shown in figures 6,7 , and 8 . Such variable substructures are found in granules of different cells as well as within a single cell (fig. 6). Many of the granules in the terminal tubules of seven day-old rats show highly organized substructures. Occasionally, the granule content has a fingerprintlike pattern which appears to be formed by electron lucent tubules of about $300 \AA$ in diameter (fig. 7). In some granules (fig. 8), the tubules are fewer and more irregularly arranged than in those granules of the fingerprint-like pattern. However, there are granules which do not show any obvious substructures or any regular arrangement of substructures (fig. 6).

\section{DISCUSSION}

The morphological characteristics, especially the difference in the organization of the ergastoplasm, shown by the acinarand duct-type cells in the terminal tubules of the developing submandibular gland are fairly similar to those of the acinar and duct cells respectively of the adult gland, which have previously been described (Scott and Pease, '59; Kurtz, '64; Tamarin and Sreebny, '65; Tamarin, '67). The secretion granules in these two types of cells also appear to be the acinar and duct-types of the adult gland. The illpreserved appearance and relatively low density shown by the granules in the acinar-type cells seem to be characteristics of the granules in the adult acinar cells as well (Scott and Pease, '59; Leeson and Jacoby, '59; Kurtz, '64; Tamarin and Sreebny, '65; Kanda, Mayfield and Ghidoni, '68). The granules of the duct-type cells are somewhat similar in appearance, with the exception of their substructures, to the granules in the granular duct of adult rats; the granules are bound by a distinct membrane and have a dense interior (Scott and Pease, '59; Tamarin and Sreebny, '65).

The acinar-type cells present in the terminal tubules might be those cells which will subsequently form acini. This seems likely in view of the observations indicating that the acinar cells "bud off" from the terminal tubules during the early stage of postnatal development (Jacoby and Leeson, '59; Leeson and Jacoby, '59). The occurrence of acinar- and duct-type cells in the secretory end-pieces of the submandibular gland has also been observed in neonatal mice (Park and Han, '70); the former type contains mucous-like granules and the latter serous granules.

The granules of widely different substructures occurring in the duct-type cells of the terminal tubules appear to be unusual, because such granules have not been observed in the submandibular gland of adult rats. Unusual forms of secretion granules have been observed in the acinar cells of the submandibular gland of adult rats during the synthetic period following the administration of a secretion stimulating drug (Kanda, Mayfield and Ghidoni, '68). These granules were thought to be 
an early form of secretion product. Granules of different density and size have also been observed during an induced state of increased synthetic activity as a result of fasting and feeding (Scott and Pease, '64). Normal submandibular glands of the adult rats also show three types of cells, i.e., an agranular cell, a light granular cell and a dark granular cell. These cells have been suggested to be in different stages of the secretory activity of the same cell type (Tamarin and Sreebny, '65). However, these granules of duct cells do not contain the unusual substructures described herein.

Wide variations which occur in the structure of the duct-type granules can be explained in two ways. The first possible explanation is that all granules are essentially the same and the granules of different siructure are those which are in various stages of the synthetic cycle. The granules of different size can be explained if the larger granules are mature forms of smaller granules; the small granules are of ten found near the Golgi region, which presumably is the site of packing the granule. Furthermore, it can be surmised that, during the maturation of the granules, the structures described as short tubules elongate and form tubules which, in turn, align into a fingerprint-like pattern. This does not seem unlikely since the diameters of these substructures are about the same.

The second possible explanation is that there are more than one type of granule, each with an independent identity and hence different structure. Obviously, a morphological study such as this cannot alone provide convincing evidence for or against either of these possibilities.

Despite the above uncertainties, one can say that the granules of the terminal tubules probably are a transitory type, before an adult type granule appears. It has been shown that the granules of the terminal tubule disappear simultaneous with the appearance of secretion granules in the granular duct (Jacoby and Leeson, '59; Leeson and Jacoby, '59; Fukuda, '67). Indeed somewhat similar transitory granules in developing submandibular glands have been reported to be present in the gland of newborn mice (Kumegawa, Cat- toni and Rose, '67) and of hedgehog (Tandler, '69).

The structural differences which are shown by the granules of the terminal tubules and those of the mature gland might be due to the difference in the chemical composition of these two granules. Previous histochemical studies have shown that the granules of the terminal tubule show staining reactions which are different from those shown by the granules in the gland of adult rats (Jacoby and Leeson, '69). Also there appears to be a difference in the enzyme content of the gland of young and adult rats; various enzymes do not reach the adult level until about five weeks after birth, which coincides with the appearance of secretory granules in the granular ducts (Fukuda, '67). Similarly, biochemical analysis of the submandibular gland has shown that the proteolytic activity of the gland increases with the increasing age of rats from about 15 days after birth (Sreebny et al., '55). Then it is not unlikely that qualitative and/or quantitative differences in the chemical composition of the secretory granules would be reflected in the substructure of these granules.

\section{LITERATURE CITED}

Fukuda, M. 1967 Histochemical studies on the rat submaxillary gland during post-natal development. Histochemie, 8: 342-354.

Jacoby, F., and C. R. Leeson 1959 The postnatal development of the rat submaxillary gland. J. Anat., 93; 201-216.

Kanda, T., E. D. Mayfield, Jr. and J. J. Ghidoni 1968 Ultrastructural alterations in submaxillary acinar cells following isoproterenol administration. Exp. Molecul. Path., 9: 189-196.

Kumegawa, M., M. Cattoni and G. G. Rose 1967 An unusual droplet in submandibular gland of new born mice. J. Cell Biol., 33: 720-723.

Kurtz, S. M. 1964 The salivary glands. In: Electron Microscopic Anatomy. S. M. Kurtz, ed. Academic Press, pp. 97-122.

Leeson, C. R., and F. Jacoby 1959 An electron microscopic study of the rat submaxillary gland during its post-natal development and in the adult. J. Anat., 93: 287-295.

Luft, J. H. 1961 Improvements in epoxy resin embedding methods. J. Biophysic. and Biochem. Cytol., 96: 409-414.

Park, J. H., and S. S. Han 1970 Studies on Hypoxia. VI. Cytologic effects of anoxia on submandibular glands of neonatal mice. Submitted for publication.

Reynolds, E. S. 1963 The use of lead citrate at high $\mathrm{pH}$ as an electron opaque stain in electron microscopy. J. Cell Biol., 17: 208-212. 
Shackleford, J. M., and E. C. Klapper 1962 Structure and carbohydrate histochemistry of mammalian salivary glands. Am. J. Anat., 111: 25-33.

Scott, B. L., and D. C. Pease 1959 Electron microscopy of the salivary and lacrimal glands of the rat. Am. J. Anat., 104: 115-161.

1964 Electron microscopy of induced changes in the salivary gland of the rat. In: Internat'l Series Monogra, Oral Biol. L. M. Sreebny and J. Meyer, eds. The MacMillan Co., pp. 13-44.

Sreebny, L. M., J. Meyer, E. Bachem and J. P. Weinmann 1955 Postnatal changes in proteolytic activity and in the morphology of the submaxillary gland in male and female albino rats. Growth, 19: 57-74.
Tamarin, A. 1967 Secretory cell alterations associated with submaxillary gland duct ligation. In: Secretory Mechanism of Salivary Glands. By L. H. Schneyer and C. A. Schneyer, eds. Academic Press, pp. 220-237.

Tamarin, A., and L. M. Sreebny 1965 The rat submaxillary gland. A correlated study by light and electron microscopy. J. Morph., 117: 295352.

Tandler, B. 1969 Ultrastructure of submandibular glands of the European hedgehog, Erinaceus europaeus L. Anat. Rec., 163: 273.

Watson, M. L. 1958 Staining of tissue sections for electron microscopy with heavy metals. J. Biophysic. and Biochem. Cytol., 4: 475-478. 


\section{PLATE 1}

EXPLANATION OF FIGURE

1 A terminal tubule of the submandibular gland from a seven day-old rat. Two types of cells constitute the tubule during the first week of the postnatal period. Acinar-type cells (AC) contain ill-preserved granules and parallel arrays of endoplasmic reticulum. Duct-type cells (DC) contain distinct granules of somewhat higher density and a small amount of irregularly arranged endoplasmic reticulum. $\times$ 5,000 . 
S. K. Kim, S. S. Han and C. E. Nasjleti

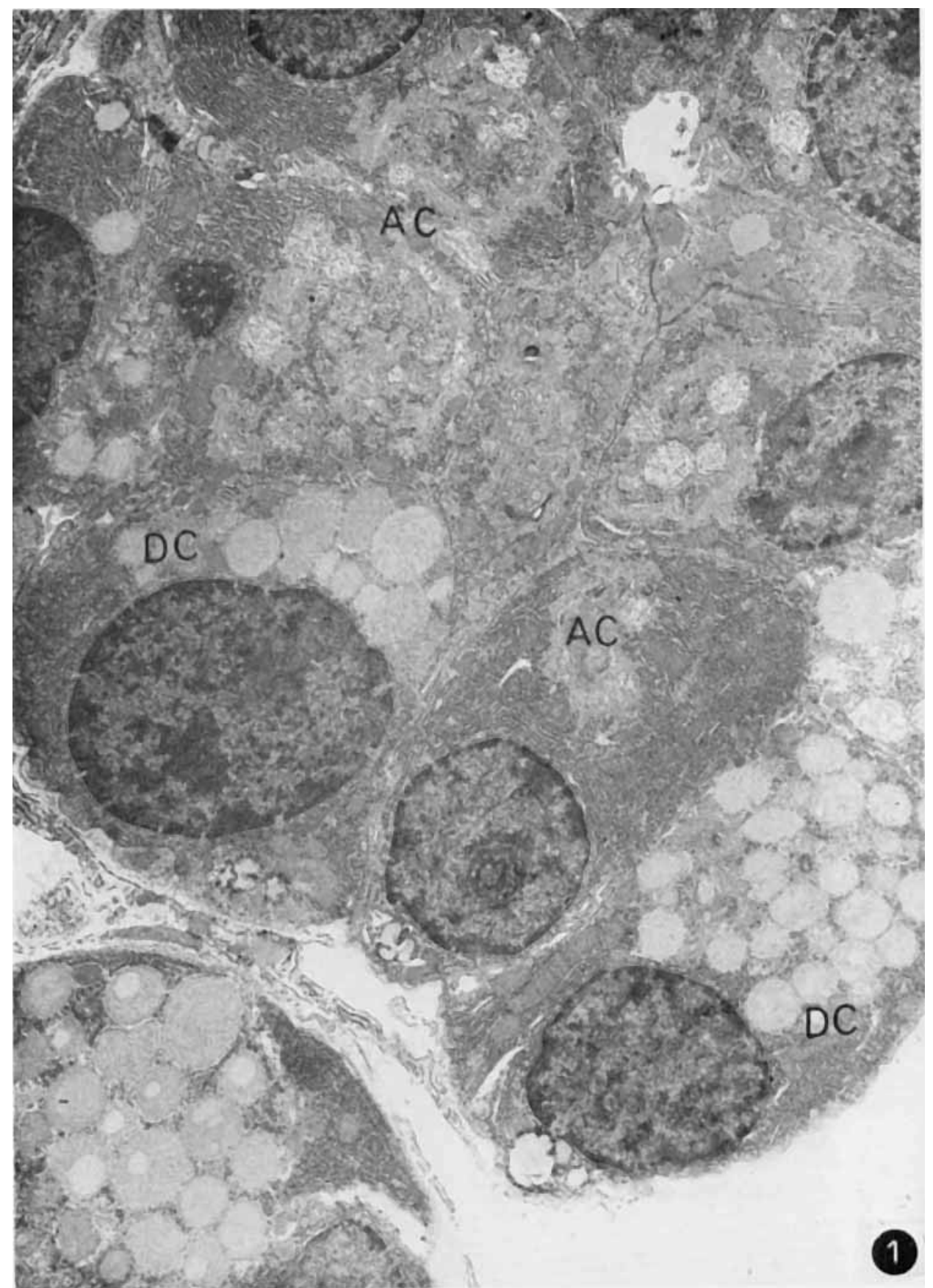


PLATE 2

EXPLANATION OF FIGURES

2 A portion of a duct-type cell from the terminal tubule of a three day-old rat. Granules of various kinds are present in the cell. Small granules (Gr) of homogeneously dense interior occur near the Golgi (Go). $\times 25,000$.

3 A type of granule which is most frequently encountered in the ducttype cells of the tubule in one day-old rats. Substructures of circular and somewhat elongated profiles occur in the granules. $\times 50,000$. 

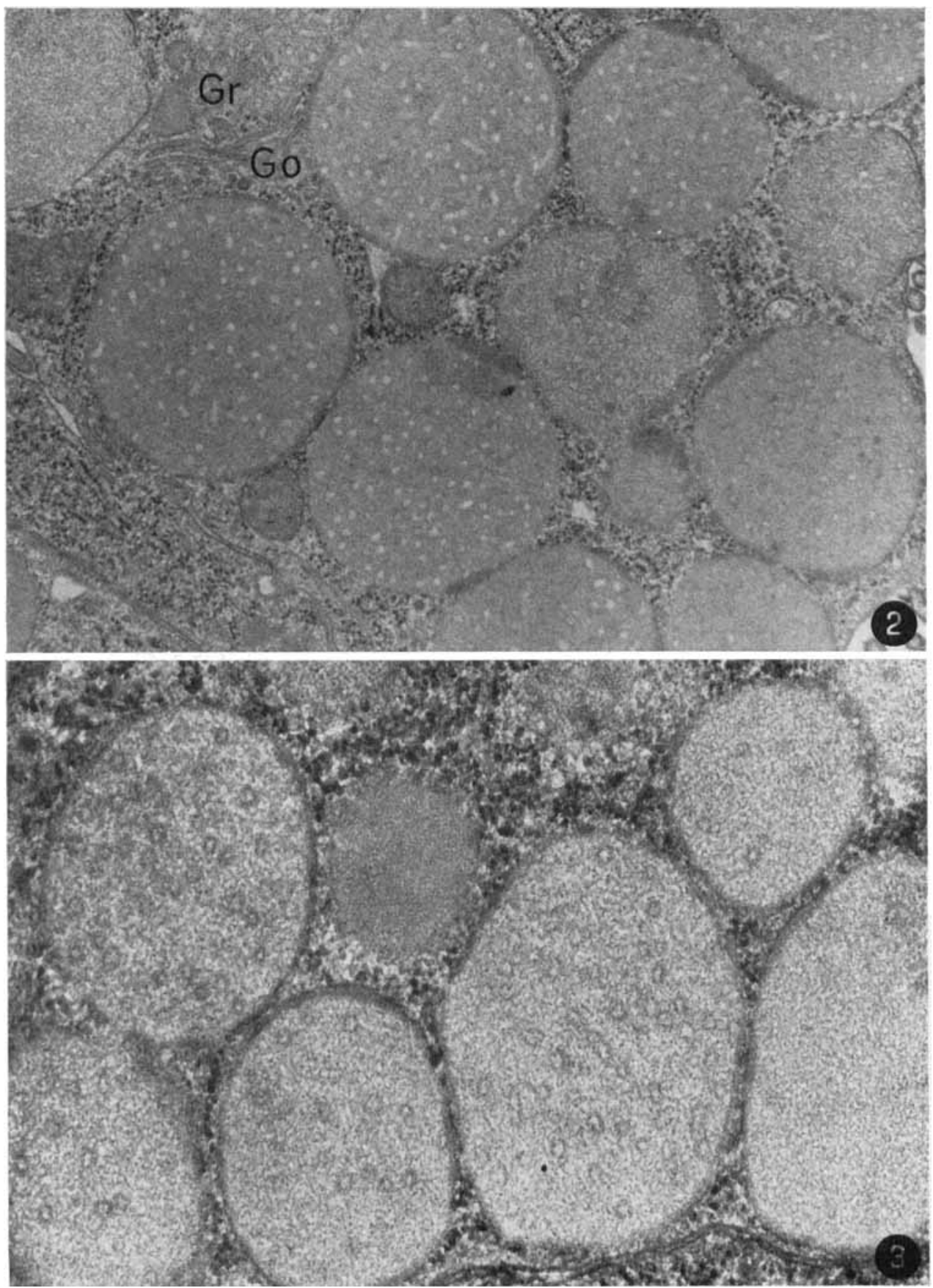
PLATE 3

EXPLANATION OF FIGURES

4-5 Granules of tubular substructures found in the duct-type cells of the terminal tubule from three day-old rats. The tubules are more clumped together in the granules shown in figure 4 than in those shown in figure 5. A small portion of nucleus $(N)$ is included in figure $5 . \times 50,000$. 

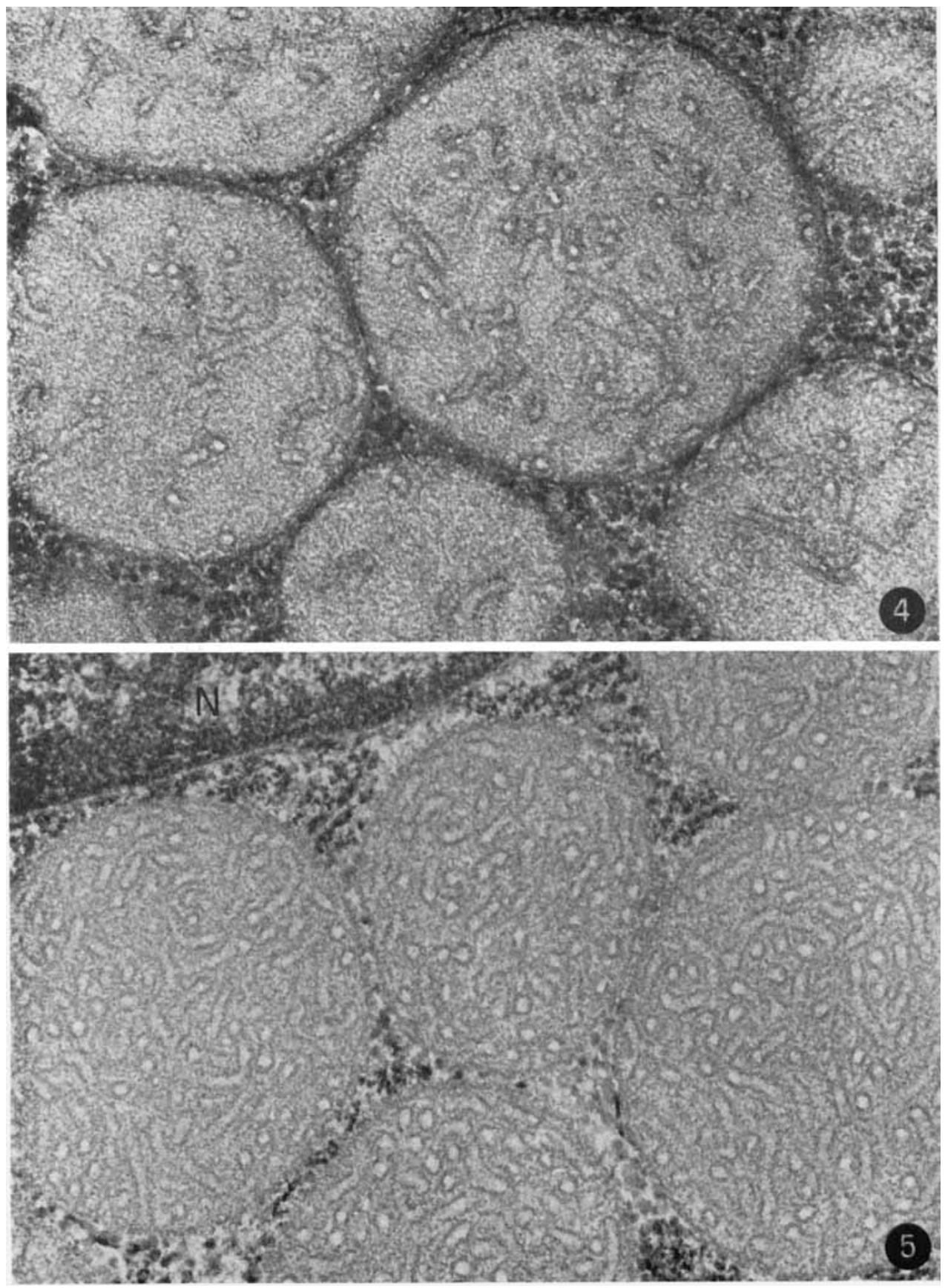
PLATE 4

EXPLANATION OF FIGURES

6 Apical portions of the duct-type cells in the terminal tubule of a seven day-old rat. Granules of various structure occur in different cells as well as within a cell. Granules reveal various substructures which are not present in the granules of younger rats. $\times 12,000$.

7-8 Granules of the duct-type cells in the terminal tubules of seven day-old rats. $\times 50,000$. 

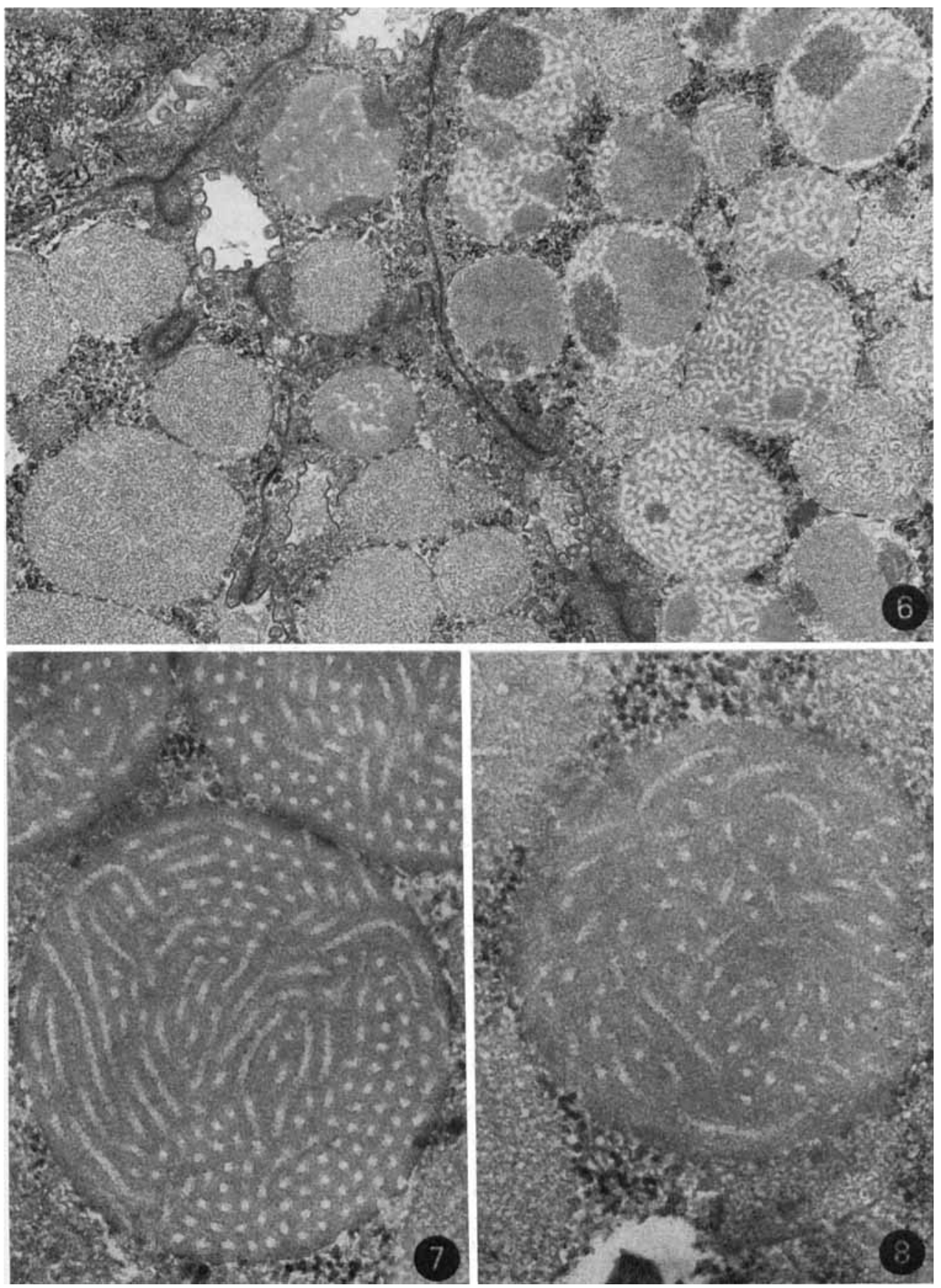